\title{
Influence of Er on Microstructure and Properties of Al-0.2\%Zr-0.06\%B Heat-resistant Alloy Conductor Prepared by Continuous ECAE Forming
}

\author{
Tian-Guo ZHOU ${ }^{\mathrm{a}}$, Zhe ZHANG $^{\mathrm{b},{ }^{,}}$, Fang-Fang ZHANG ${ }^{\mathrm{c}}$
}

College of Mechanical Engineering, Shenyang University, Shenyang, Liaoning, China

a2622166377@qq.com, b995423221@qq.com, '1010421609@qq.com

*Corresponding author

Keywords: Al-Zr-B-Er Alloy, Microstructure, Properties, Equivalent Conductivity.

\begin{abstract}
By using OP, SEM, double arm direct electric bridge, electronic universal material testing machine and electric heating high temperature drying box instrument. The effect of Er on the properties and microstructures of Al-Zr-B alloy electric conductors was studied. The results show that additive Ercan refine the grain of the alloy, increase the strength of the alloy and heat resistance and conductivity after a reasonable heat treatment. Er can react with impurity elements existing in aluminum matrix to form precipitated phase, thereby the effect of impurity elements on the conductivity of aluminum was reduced, their corresponding the electric conductivity and tensile strength improved. When the Al-0.2Zr-0.06B-0.2Er alloy soaked in the temperature of $220^{\circ} \mathrm{C}$ for $8 \mathrm{~h}$, its tensile strength and equivalent conductivity is $218 \mathrm{MPa}$ and $59.8 \% \mathrm{IACS}$ respectively. The complicated properties of Al-Zr resistant alloy wires are improved, this study is of significance.
\end{abstract}

\section{Introduction}

Electric power is the indispensable important energy of national economic development. With the rapid development of economic in our country, the demand for power is greatly increased. Sources of Electricity in our country are mostly concentrated in the west region, but the power needed in the eastern region. So large-scale electric powers must be transmitted with long distance from western china to the eastern, exchange of electric power between south and north and interconnection in the whole country has high demands for wires with saving energy, heat resistance and freeze-proofing. High strength heat resistant aluminum alloy wires with high electric conductivity were used to meet the increase of overhead conductors. However, the resistivity of heat resistant aluminum alloy conductor is too high to fit for the electric power long-distance transmission, so development of high strength with high conductivity heat resistant aluminum alloy wire has become a major task in our country[1-2]. Studies have shown that adding suitable amount of $\mathrm{Zr}$ element can effectively improve the recrystallization temperature of aluminum and increase the heat resistance of aluminum. $\mathrm{Al}-\mathrm{Zr}$ alloy conductors with low content of $\mathrm{Zr}$ are not fit for strength requirement for long distance electric power transmission. With the increase of content of $\mathrm{Zr}$, the strength of $\mathrm{Al}-\mathrm{Zr}$ alloy conductors can be increased with electric conductivity of heat-resistant alloy wire decreased rapidly. It is reported that Er can refine the grain and restrain recrystallization of aluminum alloy[3-6], reduce the effect of impurity elements on conductivity of aluminum substrate, then improved the electrical conductivity. Experiments showed that adds the right amount of $\mathrm{Zr}$ and B elements at the same time can improve the thermal stability and electrical conductivity of aluminum alloy wire[7]. Al-Zr-B-Er alloy was selected as experimental electric conductive material in this study, followed by continuous ECAE process. It is hoped to find a new method to produce high electrical conductivity -strength Al-Zr resistant heat aluminum alloy conductor.

\section{The Experimental Materials and Methods}

99.7\% industrial pure aluminum is used in experiment, its chemical composition as shown in Tab.1. Al-Zr-B-Er alloy was preparing by adding Al-5\%Zr, Al-3B\% and Al-20Er master alloys, the mass fraction of Er in the alloy were 0, 0.1, 0.2 and 0.3 respectively. Crucible furnace is used in this experiment to melt aluminum alloy. Firstly, the temperature of the crucible was preheated to 
$730^{\circ}$ Owith half an hour holding to make the crucible dry, and then industrial pure aluminum was put in clean crucible to be melted completely, then Al-5\%Zr master alloy, Al-3\%B master alloy and Al-20Er alloy added one by one with each melted completely. After degassed by using nitrogen, slag was removed, and impurity removed. When the temperature reach to $730^{\circ} \mathrm{C}$, liquidalloy were poured into the steel die to produce aluminum alloy bars with water-cooled. After then the bars were homogenized with soaking temperature $510^{\circ} \mathrm{C}$ for 6 h. Then square samples with a cross section of $12 \mathrm{mmx} 12 \mathrm{~mm}$ and length of $60 \mathrm{~mm}$ alloy rods were extruded by using homogeneous bars. Finally, the square bars were extruded by using continuous ECAE extrusion die with the $\mathrm{B}_{\mathrm{C}}$ path, the samples were prepared by 3 passes, 4 passes and 5 passes respectively. Specimens observed by using optical microscope and scanning electron microscopy (SEM). the resistance of the samples wrer measured by Using SB2230 type dc digital resistance tester, then it is converted to electrical conductivity of $20^{\circ} \mathrm{C}$. the tensile strength of the sample with the extrusion of 4 passes by using SANS CMT5105 testing machine with tensile speed $30 \mathrm{~mm} / \mathrm{min}$. Using the JCT-1 type high temperature electric heating oven insulate sample for $1 \mathrm{~h}$, the annealing temperature is $230^{\circ} \mathrm{C}, \mathrm{b}$ test the tensile strength of samples under the high temperature and then calculate the survival rate of intensity of the samples.

Tab.1 Chemical composition of Al99.70 industrial purity aluminum ingot(Wt,\%)

\begin{tabular}{ccccccc}
\hline Element & $\mathrm{Si}$ & $\mathrm{Fe}$ & $\mathrm{Cu}$ & $\mathrm{Mg}$ & $\mathrm{Cr}+\mathrm{Mn}+\mathrm{V}+\mathrm{Ti}$ & $\mathrm{Al}$ \\
Content & 0.08 & 0.13 & $<0.05$ & $<0.05$ & $<0.022$ & Bal. \\
\hline
\end{tabular}

\section{Experimental Results and Analysis}

\section{The Influence of Extrusion Times to Al-Zr-B Alloy Grain with the Continuous ECAE}

The microstructures of the Al-Zr-B-Er alloy prepared by different ECAE extrusion passes are shown in Fig.1. It can be seen that their grain size decrease with the ECAE forming passes increase, the homogeneity of the grain increase with the ECAE forming passing increase, equiaxed grains of alloy can be obtained by using 4-pass ECAE forming process. The main reason is that the material was seriously sheared by multi-pass EEAE to provide enough energy, so the secondary recrystallization and grain growth can easy occur.
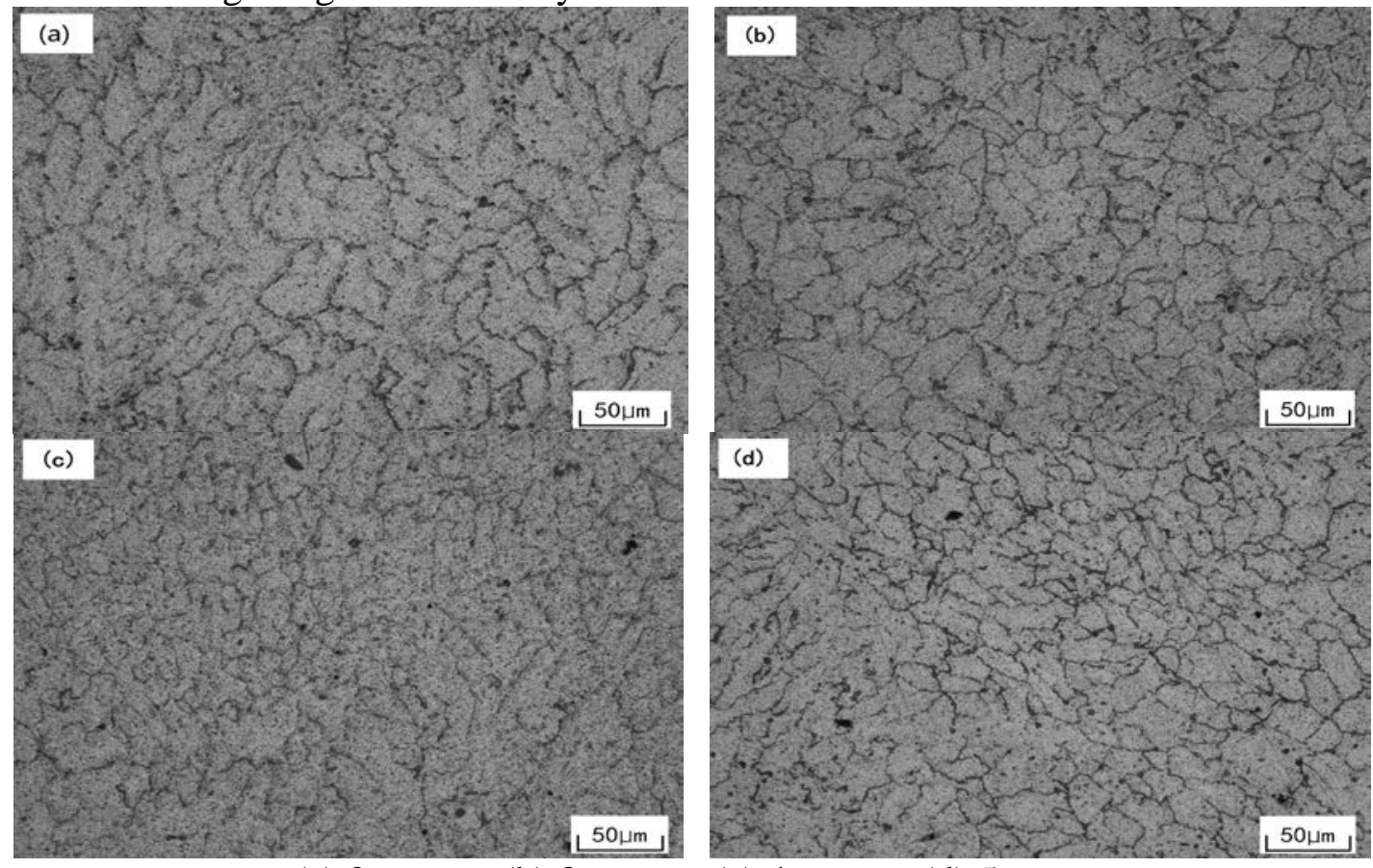

(a) 2 passes; (b) 3 passes; (c) 4 passes; (d) 5 passes

Fig.1 The microstructures of the Al-Zr-B-Er alloy prepared by different ECAE extrusion passes 


\section{The Form of the Er}

The solid solubility of Er in aluminium alloy is very small, small solid solubility leads to precipitate phase easy to precipitate and there are also many mass fraction of precipitated phase. Fig. 3 and Tab. 2 are the mass fraction of $0.3 \%$ Er which enrichment at grain boundary under SEM and the elements quality score table of EDS. By spectrum Fig.7 point can be seen, this position of Er's mass fraction have reached to $2.935 \%$, far higher than the average mass fraction of $0.3 \%$ in the aluminum substrate. Which can be speculated that after Er is added to the Al-Zr-B alloy, when the content of the Er above the solid solubility limit, Er atoms will enrich to the solid-liquid interface which atomic arrangement is irregular. At the same time from Tab.3 can be seen , this position of the Fe's mass fraction is $0.323 \%$, higher than the average mass fraction of $0.13 \%$ in aluminum matrix. May be due to the Er has strong surface activity, easy adsorb Fe and other elements of the aluminum substrate and increased the content of $\mathrm{Fe}$ and other elements in liquid phase near the interface. So in Al-Zr-B alloy organization, quite a few of the Er supersaturated solid solution in the aluminum substrate, the rest of the compound such as Al, Fe, Er phase exists in the form of grain boundary.
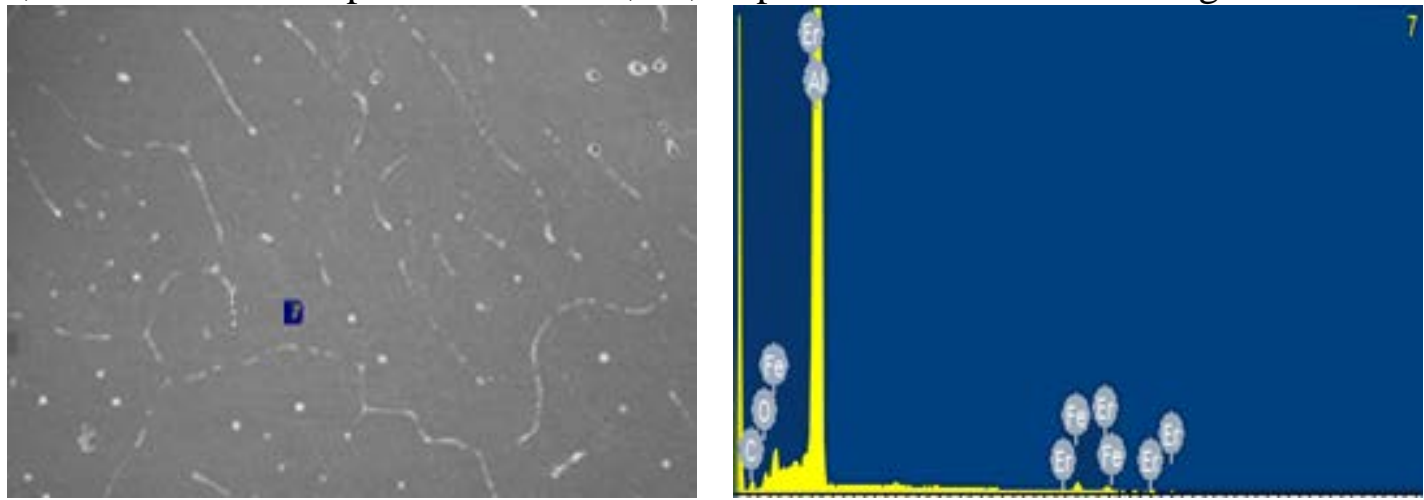

Fig.3 Mass fraction of 0.3\% Er enrich at grain boundary under SEM

Tab.2 The energy spectrum analysis of elements composition(Wt,\%)

\begin{tabular}{cc}
\hline Element & Mass fraction \\
\hline $\mathrm{C}$ & 0.051 \\
$\mathrm{O}$ & 0.057 \\
$\mathrm{Al}$ & 0.966 \\
$\mathrm{Fe}$ & 0.323 \\
$\mathrm{Er}$ & 2.935 \\
\hline
\end{tabular}

\section{The Effect of Er on the Properties of Al-Zr-B Alloy}

Tab.3 shows the main chemical composition of specimens, it can be seen that the chemical composition of $\mathrm{Zr}$ of specimen1, specimen2, specimen 3 and specimen 4 is zero, $0.1 \%, 0.2 \%$ and $0.3 \%$ respectively. Fig. 3 shows the effects of $\mathrm{Zr}$ on the tensile strength (TS) and equivalent electrical conductivity (EEC) of wires respectively. It can be seen that the tensile strength of the wires increases rapidly as the artificial aging starts. As the aging prolongs, the value increases until peak tensile strength, and then the tensile strength decrease (see Fig.3a). However, EEC (see Fig. 3(b)) increases from the beginning of the artificial aging. Because the properties of Al-Zr-B-Er alloy are determined by the hardening-precipitation phases, and the precipitation phase grows with a protracting aging time[8]. The mechanical properties (TS) can be explained by Orowan dislocation mechanism, and the EEC increases due to the diffusion of the solution elements on the free electronics, solution elements precipitated from the Al-Matrix to form hardening phase distributed in grain boundary, hardening phase weakening the diffraction to the electronic movement. It can be seen that the effect of ECAE aging process on TS changes is different from the traditional aging. 
The peak strength of specimen prepared by dynamic ECAE can be very quickly and their following TS decrease relatively slowly as aging time prolonging. The reason is that precipitate speed of solution element from Al-Matrix can be accelerated or completely, as well as the nuclei rate and growing speed of hardening phase. For example, the isothermal temperature $220^{\circ} \mathrm{G}$ aging for $8 \mathrm{~h}$, the TS and EEC of Al-0.2\%Zr-0.06B\%-0.2Er\% alloy conductors(specimen3) is $228 \mathrm{MPa}$ and $58.3 \%$ IACS respectively.

Compared with those Al-Zr resistant heat alloy prepared by traditional forming process, the TS and IACS\% of the wire prepared by CDECAE followed by a final aging process are higher than that of them. Table 3 shows that with the increase of content of Er, the tensile strength of the alloy increase obviously. with the increase of the content of Er, the conductivity of alloy increase till the content of Er reach $0.2 \%$, the conductivity reach maximum, further add the content of the Er, the conductivity of the alloy reduce instead. Show that when content of Er was $0.2 \%$, the effect of Er on the conductivity of alloy is the most obvious, and the conductivity of alloy is the highest.

Tab.3 Main chemical composition of specimens (Wt, \%)

\begin{tabular}{cccc}
\hline Alloy No. & Er & Zr & B \\
\hline 1 & 0 & 0.2 & 0.06 \\
2 & 0.1 & 0.2 & 0.06 \\
3 & 0.2 & 0.2 & 0.06 \\
4 & 0.3 & 0.2 & 0.06 \\
\hline
\end{tabular}
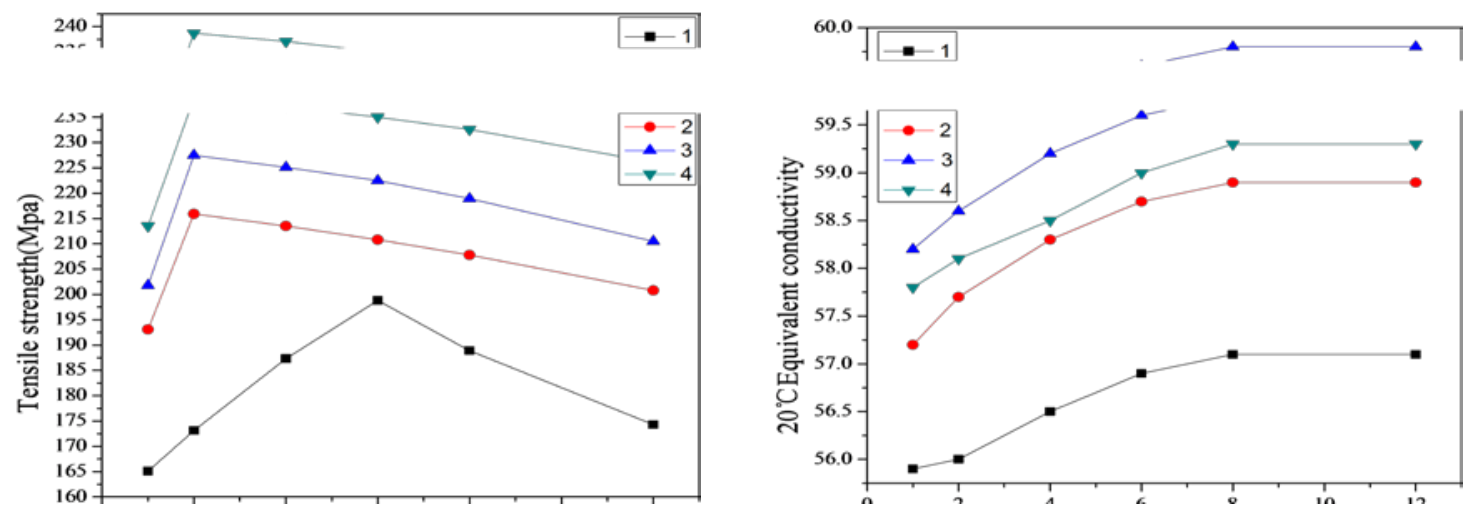

Fig. 4 The effect of ageing time on Al-Zr-B-Er alloy performance at $220^{\circ} \mathrm{C}$

Tab.4 Electrical conductivities of Al-Zr-B-Er alloy aged at $220^{\circ} \mathrm{C}$ for $8 \mathrm{~h}$

\begin{tabular}{cccc}
\hline Style No. & $\begin{array}{c}20^{\circ} \text { EElectrical } \\
\text { conductivity/IACS }\end{array}$ & $\begin{array}{c}\text { Tensile } \\
\text { strength/MPa }\end{array}$ & $\begin{array}{c}\text { The survival rate } \\
\text { of intensity /\% }\end{array}$ \\
\hline 1 & 57.1 & 188.9 & 89.1 \\
2 & 58.9 & 207.8 & 90.7 \\
3 & 59.8 & 218.9 & 91.3 \\
4 & 59.3 & 232.6 & 91.5 \\
\hline
\end{tabular}

It may be found that Er can react with impurities such as $\mathrm{Fe}, \mathrm{Si}$, $\mathrm{Cr}$ within alloy, then generate sediment precipitate to the bottom of the furnace, reduced the effects of impurity elements on electrical conductivity of aluminum alloy and improved the conductivity. Redundant Er can react 
with $\mathrm{Al}$ forming $\mathrm{Al}_{3} \mathrm{Er}$ precipitated phase, $\mathrm{Al}_{3} \mathrm{Er}$ precipitate from the alloy firstly, $\mathrm{Al}_{3} \mathrm{Zr}$ and $\mathrm{Al}_{3}(\mathrm{ZrEr})$ will also gradually precipitate in the subsequent heat treatment, so EEC of specimens increase with the aging time prolonged.

\section{Conclusion}

1) The grain size of Al-Zr-B-Er alloy wires decrease with the ECAE forming passes increase, the homogeneity of the grain increase with the ECAE forming passing increase, equiaxed grains of alloy can be obtained by using 4-pass ECAE forming process.

2) The optimization process for producing Al-Zr-B\%-Er\% alloy conductors is obtained in this study. When the isothermal temperature $220^{\circ} \mathrm{C}$ aging for $8 \mathrm{~h}$, the TS and EEC of $\mathrm{Al}-0.2 \% \mathrm{Zr}-0.06 \mathrm{~B} \%-0.2 \mathrm{Er} \%$ alloy conductors $\quad$ is $218 \mathrm{MPa}$ and $58.3 \% \mathrm{IACS}$ respectively.

\section{Acknowledgement}

This research is financially supported by National Natural Science Foundation (51174139).

\section{References}

[1]D. Y. Liu, J.J. Liu, S.X. Hou, et al. Development of heat-resistant aluminum alloy wire, J. Heat treatment technology and equipment, 34(3) (2013)1-5.

[2]J. Li, Y. Q. Zhang, J. Lu. Application of a new type in wire in Xiamen $220 \mathrm{kV}$ cross sea passage rehabilitation, J. Electric power construction, 30 (1) (2009)86 -90.

[3]Z. W. Nie, H. Zuo, S. P. Wen, H. Huang, et al. Research progress of bait micro alloyed aluminum alloy, J. China Journal of nonferrous metals, 21 (10) (2011) 2361 -2370.

[4]J.J. Yang, Z.R. Nie, T. N. Jin, et al. The effect of trace rare earth element Eron Recrystallization Behavior of high pure aluminum, J. Rare metal materials and engineering, 32(1) (2003):37-40.

[5]T. G. Zhou, Z. Y Jing, J. L Wen, et al. Semi-solid Continuous Casting-extrusion of AA6201 Feed Rods, J. Science and Engineering A,2008,485(1/2):108-114.

[6]Y. J. Yang, G. F. Xu, Z. R. Nie, et al. The effect of trace Er on the microstructure and properties of high strength aluminum alloy, J. The special casting and nonferrous alloys, 26(7) (2006)393-396.

[7]G. Q. Wang, et al. The effect of Boron pure aluminum conductive fields, Journal of metal,2000, 36(6): 598-601.

[8]J. E Hatch. Aluminum properties and physical metallurgy, J.ASM, 983 :202-240. 